\title{
MENGENAL PASTI KEPERLUAN PEMBINAAN MODEL KANDUNGAN KURIKULUM PENDIDIKAN KEAMANAN BERASASKAN MULTIBUDAYA UNTUK KANAK-KANAK PRASEKOLAH
}

\author{
Identifying Needs for Development of Multicultural-Based Model of Peace Education \\ Curriculum for Preschool Children
}

\author{
Noor Amy Afiza Mohd Yusof ${ }^{1}$, Saedah Siraj ${ }^{2}$, Mariani Md Nor ${ }^{3}$, Azli Ariffin ${ }^{4}$ \\ Fakulti Pendidikan, Universiti Malaya Kuala Lumpur, Malaysia 1, 2, 3 , \\ Fakulti Pembangunan Manusia, Universiti Pendidikan Sultan Idris, Tg Malim, Perak, \\ Malaysia $^{4}$ \\ amy_eja86@yahoo.com ${ }^{1}$, saedah@um.edu.my ${ }^{2}$, marianin@um.edu.my ${ }^{3}$, \\ azli@fppm.upsi.edu.my ${ }^{4}$
}

\begin{abstract}
ABSTRAK
Keamanan merupakan isu yang sering diperkatakan belakangan ini terutamanya yang melibatkan kepelbagaian budaya. Melalui pendidikan, keamanan dapat disampaikan kepada semua peringkat terutamanya kanak-kanak yang merupakan pewaris generasi akan datang. Kajian ini dijalankan bagi mengenal pasti keperluan dalam pembinaan Model Kandungan Kurikulum Pendidikan Keamanan Berasaskan Multibudaya untuk Kanak-kanak Prasekolah. Keperluan berkenaan meliputi keperluan pembinaan dan keperluan isi kandungan. Kajian ini menggunakan kaedah soal selidik bagi mengenal pasti tahap keperluan bagi kedua-dua keperluan berkenaan. Satu soal selidik 5 skala likert ditadbir kepada 200 orang guru prasekolah yang dipilih secara rawak di Semenanjung Malaysia. Nilai min bagi setiap konstruk keperluan dinilai bagi memperoleh tahap keperluan yang diperlukan. Nilai min yang diperoleh bagi keperluan pembinaan kandungan kurikulum adalah sebanyak 4.2879 manakala bagi keperluan isi kandungan kurikulum ialah 4.2480. Berdasarkan nilai min yang diperolehi jelas menunjukkan bahawa terdapat keperluan pembinaan dan keperluan isi kandungan apabila julat persetujuan yang diberikan berada dalam skala 4 hingga 5 iaitu sangat setuju.
\end{abstract}

Kata kunci: pendidikan keamanan, kandungan kurikulum, kanak-kanak prasekolah, keperluan pembinaan, keperluan isi kandungan

\begin{abstract}
Peace is an issue that is often said recently, involving cultural diversity. Through education, peace can be delivered to all levels, especially children who are the next generation of heirs. This study was conducted to identify the needs for the development of Multicultural-Based Model of Peace Education Curriculum for Preschool Children. The requirements cover development requirements and content requirements. This study uses a questionnaire to identify the level of need for both requirements. A Likert 5 questionnaire was conducted to 200 preschool teachers randomly selected in Peninsular Malaysia. The mean value of each construct need have been assessed for the required level of need. The mean value obtained for curriculum content development is 4.2879 while the curriculum content requirement is 4.2480. Based on the mean value obtained clearly indicates that there is a development requirements and content requirements when the range of consent is given on a scale of 4 to 5 which is strongly agreed.
\end{abstract}

Keywords: peace education, curriculum contents, preschool children, development requirements, contents requirements 


\section{PENGENALAN}

Budaya keamanan dan tiada keganasan melibatkan hak asasi manusia dari aspek sosial keadilan, demokrasi, celik, rasa hormat dan maruah untuk semua, perpaduan antarabangsa, menghormati hak-hak pekerja dan piawaian buruh teras, hak kanak-kanak, kesaksamaan di antara lelaki dan wanita, identiti budaya dan kepelbagaian, hak orang asal dan minoriti, pemeliharaan alam semula jadi serta beberapa lagi tema yang jelas.

Tindakan pendidikan untuk mempromosikan konsep keamanan menekankan kandungan pendidikan dan latihan, sumber pendidikan dan bahan, sekolah dan kehidupan universiti, latihan awal dan berterusan untuk guru-guru, penyelidikan dan latihan yang berterusan untuk anak-anak muda dan orang dewasa. Budaya keamanan mesti berakar umbi di dalam kelas dari usia muda. Ia mesti terus dapat dilihat dalam kurikulum di setiap peringkat.

Walau bagaimanapun, kemahiran untuk keamanan dan bukan keganasan hanya boleh dipelajari dan disempurnakan melalui amalan. Mendengar secara aktif, dialog, pengantaraan dan pembelajaran koperatif adalah kemahiran halus yang perlu berkembang. Ini adalah pendidikan dalam erti kata yang luas. Ia adalah satu proses jangka panjang dinamik iaitu satu pengalaman seumur hidup. Ini bermakna menyediakan kedua-dua kanak-kanak dan orang dewasa dengan memahami dan menghormati nilai-nilai dan hak asasi sejagat. Ia memerlukan penglibatan semua pihak termasuk keluarga, sekolah, tempat kerja, bilik berita, tempat bermain dan masyarakat serta negara.

Sejak awal abad ke-20, program "Pendidikan keamanan" di seluruh dunia telah mempersembahkan spektrum tema berfokus, termasuk anti-nuklear, pemahaman antarabangsa, tanggungjawab alam sekitar, kemahiran komunikasi, anti-keganasan, teknik penyelesaian konflik, demokrasi, kesedaran tentang hak asasi manusia, kepelbagaian toleransi, kewujudan bersama dan kesaksamaan gender antara satu sama lain (Groff \& Smoker, 1996; Harris, 1998; Johnson, 1998; SweeHin Toh, 1997). Semakin banyak wacana akademik mengenai perkara ini telah diiktiraf keperluannya, semakin tinggi juga penggunaan pendekatan yang lebih holistik dan meluas dalam pendidikan keamanan, dapat dilihat terdapat tiga pendedahan variasi mengenai pendidikan keamanan daripada sorotan kajian yang telah dijalankan. Variasi berkenaan ialah latihan penyelesaian konflik, pendidikan demokrasi, dan pendidikan hak asasi manusia. Pendekatan-pendekatan baharu yang muncul hanya dipersoalkan dari segi teori-teori asas model sahaja. Yang paling penting pendekatan baru ini memberi tumpuan kepada pendidikan keamanan sebagai satu proses transformasi pandangan dunia (Wikipedia, 2015).

Konteks pendidikan harus menyediakan program menangani keganasan psikologi dan fizikal, termasuk pembuli siber, melalui pencegahan keganasan, penyelesaian konflik dan pengantaraan dalam semua peringkat pendidikan. Pendidikan Keamanan adalah merupakan komponen penting dalam pendidikan asas yang berkualiti. UNICEF (1999a) mentakrifkan pendidikan keamanan sebagai proses menggalakkan pengetahuan, kemahiran, sikap dan nilai-nilai yang diperlukan untuk membawa perubahan tingkah laku yang akan membolehkan kanak-kanak, belia dan orang dewasa untuk mengelakkan konflik dan keganasan, kedua-dua struktur dan terang-terangan; untuk menyelesaikan konflik secara aman; dan untuk mewujudkan keadaan kondusif kepada keamanan, sama ada pada intrapersonal, interpersonal, antara kumpulan, peringkat kebangsaan atau antarabangsa.

Selalunya teori atau falsafah pendidikan keamanan telah diandaikan dan tidak dinyatakan. Johan Galtung pada tahun 1975 telah mencadangkan bahawa tiada teori pendidikan keamanan yang wujud dan jelas menunjukkan tiada keperluan segera bagi teori tersebut. Pembinaan teori-teori ini hanya berlaku sejak belakangan ini. Calleja (1991) telah mencadangkan bahawa falsafah pendidikan keamanan mungkin ditempatkan di Kantian. Page (2008) juga telah mencadangkan bahawa rasional untuk pendidikan keamanan mungkin terletak dalam etika kuasa, etika consequentialist, etika politik konservatif, etika estetika dan etika penjagaan. 
Dalam persekitaran pendidikan kaedah pengajaran dan pembelajaran boleh dinaik taraf dengan menerapkan pendekatan baharu seperti penggunaan teknologi digital untuk meningkatkan pembelajaran pelajar. Pelajaran ini bukan sahaja untuk diajar di dalam kelas, malah untuk persediaan kehidupan luar yang memberi kuasa kepada individu untuk mencapai satu masyarakat yang adil di mana semua hak asasi manusia dihargai dan dihormati. Pendidikan keamanan juga perlu ada dalam kandungan semua kurikulum di setiap peringkat dalam sistem pendidikan. Pendidikan keamanan perlu diperluaskan kepada semua pelajar, termasuk pelarian dan kanak-kanak asing, kanak-kanak daripada golongan minoriti dan orang kurang upaya dengan objektif untuk mempromosikan peluang yang sama melalui pendidikan.

\section{TUJUAN KAJIAN}

Kajian ini bertujuan untuk mengenal pasti tahap keperluan pembinaan Model Kandungan Kurikulum Pendidikan Keamanan Berasaskan Multibudaya untuk Kanak-kanak Prasekolah. Objektif bagi kajian ini ialah:

a. Mengenal pasti tahap keperluan pembinaan Model Kandungan Kurikulum Pendidikan Keamanan Berasaskan Multibudaya untuk Kanak-kanak Prasekolah.

b. Mengenal pasti keperluan kandungan yang diperlukan dalam pembinaan Model Kandungan Kurikulum Pendidikan Keamanan Berasaskan Multibudaya untuk Kanak-kanak Prasekolah.

\section{METODOLOGI KAJIAN}

Terdapat lima (5) kaedah yang boleh digunakan bagi mendapatkan data kajian. Kaedah-kaedah berkenaan ialah soal selidik, temu bual, pemerhatian, ujian dan dokumen. Bagi kajian ini, penyelidik memilih untuk menggunakan soal selidik 5 skala likert. Soal selidik boleh didefinisikan sebagai satu set soalan atau pernyataan untuk mendapatkan maklumat objektif sesuatu penyelidikan. Soal selidik merupakan cara yang ringkas bagi mendapatkan maklumat. Menurut Mohd Majid (2004), penggunaan soal selidik lebih praktikal berkesan apabila melibatkan populasi yang besar. Penyelidik menggunakan soal selidik kerana ianya mudah difahami dan tidak kabur. Di samping itu juga, responden lebih mudah untuk memahami tujuan kutipan data itu dilakukan. Tambahan pula, soal selidik memiliki kesahan dan kebolehpercayaan yang tinggi.

Soal selidik ini dibina dengan rujukan kajian terdahulu. Namun begitu, ianya telah diubah suai sesuai dengan latar belakang kajian dan persoalan kajian. Menurut Sheatley dalam Syed Arabi (1998) menyatakan bahawa soal selidik yang baik seharusnya boleh mencapai tujuan kajian dengan perbelanjaan yang sederhana. Tujuan soal selidik ialah untuk mendapatkan data daripada sampel kajian. Manakala menurut Wei Chooi Yi (2009) soal selidik digunakan dalam kajian kerana dapat menjimatkan masa dan membolehkan responden menjawab soalan soal selidik tanpa bimbingan dan intervensi secara langsung daripada penyelidik. Kebaikan menggunakan kaedah soal selidik ini ialah jika ia disediakan dengan baik, maka ia dapat menghasilkan item-item yang konsisten dan boleh dipercayai (Cates, 1990d).

Penggunaan soal selidik berbentuk item tertutup dan jawapan terpilih amat baik kerana responden tidak memerlukan masa yang panjang untuk berfikir atau melahirkan idea-idea baru terhadap pertanyaan yang diajukan (Kerlinger, 1986). Menurut Marshall dan Rossman (1989), soal selidik yang mempunyai kekuatan dalam menjalankan kajian perlu mempunyai ciri-ciri berikut:

a. Mudah untuk memanipulasi dan mengkategorikan data untuk dianalisis

b. Mengurus dan mentadbir data dengan mudah dan berkesan

c. Mudah untuk membuat generalisasi 
Namun begitu, sebelum soal selidik ini ditadbir, soal selidik ini terlebih dahulu melalui proses kajian rintis. Bagi permulaan peringkat mengumpul data, proses pembinaan item perlulah berjalan dengan betul. Proses pembinaan item soalan perlu melalui beberapa peringkat, iaitu pemilihan soalan yang bersesuaian dengan objektif kajian, penyusunan soalan yang betul dan perlu diuji terlebih dahulu menggunakan Cronbach Alfa. Ini bagi membuktikan item yang dipilih bersesuaian. Setelah item-item soalan tadi menjadi soal selidik, kajian rintis perlu dijalankan terlebih dahulu sebelum data sebenar dikumpul. Menguji soal selidik melalui kajian rintis bererti satu ujian skala kecil (small-scale testing) (Pratt, 1980).

Kajian rintis dijalankan untuk menentukan kesahan dan kebolehpercayaan instrumen kajian yang digunakan oleh pengkaji. Kajian rintis yang dijalankan ini dapat menentukan ketepatan dan ketekalan item-item yang dibina dalam soal selidik. Fraenkel dan Wallen (1996) telah mendefinisikan kajian rintis sebagai satu cubaan kajian yang dibuat secara kecilan yang bertujuan untuk mengenal pasti kelemahan alat dan tatacara kajian.

\section{SAMPEL KAJIAN}

Seramai 200 orang guru prasekolah telah dipilih secara rawak di seluruh Semenanjung Malaysia bagi menjawab soal selidik yang telah dibina. Pemilihan sampel dari kalangan guru prasekolah adalah berikutan mereka merupakan golongan pelaksana kurikulum. Oleh yang demikian, mereka lebih arif tentang keperluan yang diperlukan di prasekolah.

\section{INSTRUMEN KAJIAN}

Instrumen yang digunakan dalam kajian ini ialah soal selidik 5 skala likert. Instrumen ini dibahagikan kepada dua bahagian, iaitu bahagian A (keperluan pembinaan model) dan bahagian B (keperluan pembinaan kandungan model). Bahagian A soal selidik ini ialah untuk melihat sejauh mana pendidik prasekolah memerlukan satu model kandungan kurikulum sebagai bantuan kepada mereka dalam membentuk keperibadian kanak-kanak prasekolah ke arah individu yang aman. Dapatan bagi bahagian ini akan menentukan sama ada wujudnya keperluan kepada pembinaan kandungan kurikulum ini atau sebaliknya. Bahagian ini mengandungi tujuh penyataan yang memerlukan guru memilih jawapan mengikut tahap persetujuan mereka dengan penyataan yang diajukan.

Bahagian B pula adalah bahagian keperluan kandungan model. Bahagian ini mengandungi tiga puluh (30) soalan berkaitan Model Kandungan Kurikulum Pendidikan Keamanan Berasaskan Multibudaya untuk Kanak-kanak Prasekolah iaitu pengetahuan, kemahiran dan nilai. Hasil ini akan menentukan sama ada kandungan yang bakal dimuatkan dalam kandungan kurikulum berkenaan bersesuaian atau tidak, selari dengan tujuan kajian ini dijalankan. Guru perlu menyatakan tahap persetujuan mereka terhadap kesemua penyataan yang diajukan.

\section{ANALISIS KAJIAN}

Analisis data merupakan fasa penting dalam sesebuah kajian. Ini kerana dengan penggunaan teknik yang betul, data yang dikeluarkan akan sangat berguna. Penyelidik mengumpulkan semua data kuantitatif yang telah diperolehi daripada soal selidik dan menganalisisnya dengan menggunakan program SPSS versi 20.0.

Analisis dibuat secara statistik deskriptif. Mengikut Mohd Majid (2004) statistik deskriptif ialah kaedah statistik yang digunakan untuk meringkaskan, merumus, mempersembahkan data yang diperoleh agar data itu dapat memberi maklumat yang bermakna. Analisis deskriptif akan digunakan untuk melaporkan tahap persetujuan keseluruhan guru prasekolah tentang item-item yang disoal. 
Laporan berkaitan keperluan pembinaan Model Kandungan Kurikulum Pendidikan Keamanan Berasaskan Multibudaya untuk Kanak-kanak Prasekolah akan dapat dilihat berdasarkan analisis yang dijalankan. Setiap item dianalisis menggunakan data deskriptif dalam bentuk frekuensi $(\mathrm{N})$, peratusan (\%) dan min.

\section{DAPATAN KAJIAN}

Kajian sebenar analisis keperluan dijalankan setelah hasil dapatan kajian rintis menunjukkan tiada perubahan yang perlu dilakukan terhadap soal selidik yang telah dibina. Hasil dapatan kajian ini dibahagikan kepada dua bahagian seperti mana soal selidik yang telah diedarkan kepada responden. Bahagian-bahagian berikut ialah bahagian A iaitu (keperluan pembinaan kandungan kurikulum) dan bahagian B (keperluan isi kandungan kurikulum). Bahagian A mengandungi 7 item yang dikemukakan berdasarkan keperluan pembinaan kandungan kurikulum. Penyataan yang dikemukakan bagi konstruk keperluan pembinaan ini adalah seperti berikut:

1. Saya setuju bahawa untuk menerapkan konsep pendidikan keamanan perlukan kurikulum yang lengkap sebagai panduan.

2. Saya memerlukan panduan untuk mengajar pendidikan keamanan kepada kanak-kanak.

3. Saya faham bahawa pendidikan keamanan untuk kanak-kanak mempunyai proses tertentu.

4. Saya memerlukan bimbingan dalam proses mengajar pendidikan keamanan kepada kanakkanak.

5. Saya faham bahawa kanak-kanak perlu dibimbing dengan betul bagi menjadikan mereka individu yang aman dan seimbang.

6. Saya setuju bahawa proses menjadikan kanak-kanak individu yang aman dan seimbang perlu berasaskan kepada kandungan kurikulum yang sesuai.

7. Saya setuju bahawa perlu dibina satu kandungan kurikulum pendidikan keamanan berasaskan multibudaya untuk kanak-kanak prasekolah bagi membantu guru dalam pengajaran.

Setiap item dinilai berdasarkan frekuensi (N) dan peratusan (\%) yang diterima daripada keseluruhan 200 orang responden. Hasil analisis yang diterima bagi setiap item menunjukkan bahawa majoriti responden memilih bersetuju dengan setiap item yang dikemukakan. Berdasarkan keseluruhan tujuh (7) item yang disoal, satu rumusan berdasarkan nilai min dibuat seperti dalam jadual 1.

Jadual 1 Min Keseluruhan Konstruk Keperluan Pembinaan

\begin{tabular}{lccc}
\hline & FREKUENSI (N) & MIN & SISIHAN PIAWAI \\
\hline Pembinaan & 200 & 4.2879 & 0.4604 \\
\hline
\end{tabular}

Jadual 1 menunjukkan nilai min bagi keseluruhan konstruk keperluan pembinaan Model Kandungan Kurikulum Pendidikan Keamanan Berasaskan Multibudaya untuk Kanak-kanak Prasekolah. Nilai min yang diperolehi adalah 4.2879. Ini menunjukkan bahawa responden memilih untuk sangat setuju dengan keperluan pembinaan. Ini kerana tahap persetujuan keperluan kepada pembinaan kandungan kurikulum berada dalam julat di antara setuju dan sangat setuju. Jelas menunjukkan bahawa satu Model Kandungan Kurikulum Pendidikan Keamanan Berasaskan Multibudaya untuk Kanak-kanak Prasekolah perlu dibina sebagai panduan dan bimbingan dalam pengajaran guru bagi menjadikan kanak-kanak individu yang aman dan seimbang.

Bahagian B mengandungi 30 item yang dikemukakan berdasarkan keperluan isi kandungan kurikulum. Setiap item yang dikemukakan dalam konstruk keperluan kandungan dianalisis berdasarkan frekuensi $(\mathrm{N})$ dan peratusan (\%) yang diterima daripada keseluruhan responden. Hasil analisis menunjukkan majoriti daripada 200 orang responden yang terlibat menyatakan mereka bersetuju dengan keseluruhan 30 item yang telah dikemukakan. Oleh yang demikian, satu rumusan bagi keseluruhan konstruk keperluan kandungan berdasarkan nilai min dibuat seperti dalam jadual 2 . 
Jadual 2 Min Keseluruhan Konstruk Keperluan Isi Kandungan

\begin{tabular}{lccc}
\hline & FREKUENSI (N) & MIN & SISIHAN PIAWAI \\
\hline Kandungan & 200 & 4.2480 & 0.3427 \\
\hline
\end{tabular}

Jadual 2 menunjukkan nilai min bagi keseluruhan konstruk keperluan isi kandunagan dalam pembinaan Model Kandungan Kurikulum Pendidikan Keamanan Berasaskan Multibudaya untuk Kanak-kanak Prasekolah. Nilai min yang diperolehi adalah 4.2480. Ini menunjukkan bahawa responden memilih untuk sangat setuju dengan keperluan isi kandungan. Ini kerana tahap persetujuan keperluan kepada isi kandungan kurikulum berada dalam julat di antara setuju dan sangat setuju. Jelas menunjukkan bahawa isi kandungan kurikulum pendidikan keamanan berasaskan multibudaya untuk kanak-kanak prasekolah perlu dibina bagi melengkapkan lagi panduan dan bimbingan dalam pengajaran guru bagi menjadikan kanak-kanak individu yang aman dan seimbang.

\section{KESIMPULAN}

Secara keseluruhan, kajian ini telah memperjelaskan hasil dapatan bagi kajian yang telah dijalankan. Berdasarkan kepada objektif kajian yang telah diwujudkan di awal kajian, dapatan menunjukkan terdapat keperluan dari aspek panduan, bimbingan dan proses dalam membantu guru prasekolah menerapkan pendidikan keamanan berasaskan multibudaya untuk kanak-kanak prasekolah. Oleh yang demikian, dapat disimpulkan bahawa guru sangat bersetuju agar dibina satu Model Kandungan Kurikulum Pendidikan Keamanan Berasaskan Multibudaya untuk Kanak-kanak Prasekolah.

Seterusnya, dapatan kajian ini juga telah memperlihatkan tahap persetujuan guru berkaitan isi kandungan yang perlu dimasukkan dalam kandungan kurikulum yang akan dibina. Bagi menjawab persoalan ini, sebanyak 30 item berkaitan isi kandungan telah dikemukakan berdasarkan kepada kajian literature. Secara keseluruhannya, guru bersetuju dengan kesemua item yang dikemukakan untuk dijadikan sebagai panduan kepada pembinaan isi kandungan kurikulum yang dibina. Oleh yang demikian, berdasarkan kepada hasil dapatan kajian ini, Model Kandungan Kurikulum Pendidikan Keamanan Berasaskan Multibudaya untuk Kanak-kanak Prasekolah dapat dibangunkan.

\section{RUJUKAN}

Calleja, J. J. (1991). A Kantian Epistemology of Education and Peace: An Examination of Concepts and Values. Unpublished PhD Thesis. University of Bradford. Department of Peace Studies.

Cates, W.M. (1990a). Helping students learn to think critically: Detecting and analyzing bias in films. The Social Studies, 81, 15-18.

Cates, W.M. (1990b). Adding professional recording effects to instructional audiotapes. The Clearing House, 63, 405-410.

Cates, W. M. (1990c). A practical guide to educational research. Allyn and Bacon.

Cates, W.M. (1990d). Panduan amali untuk penyelidikan pendidikan. \{S. Abdullah, Trans., A practical guide to educational research\}. Malaysia, Kuala Lumpur: Dewan Bahasa dan Pustaka \& Allyn and Bacon.

Fraenkel, J.R \& Wallen, N.E. (1996). How to design and evaluate research in education. Third Edition. New York: Mc Graw Hill

Galtung, J. (1975). Peace: Research, Education, Action. Essays in Peace Research, 1. Copenhagen: Christian Ejlers.

Groff, L., \& Smoker, P. (1996). Creating global-local cultures of peace. Peace and Conflict Studies Journal, 3. Harris, I. (1998). Peace education. Jefferson, NC: McFarland.

Johnson, M. L. (1998). Trends in peace education. ERIC Clearinghouse for Social Studies/Social Science Education, Indiana University.

Kerlinger, F. N. (1986). Foundations of behavioral research (3rd ed.). New York: Holt, Rinehart and Winston. Marshall, C. and Rossman, G. B. (1989) Designing Qualitative Research. Newbury Park, CA: Sage Publications. Mohd Majid Konting (2004). Kaedah Penyelidikan Pendidikan. Kuala Lumpur: Dewan Bahasa dan Pustaka. 
Page, J. S. (2008). Philosophy of Peace Education. In B., Monisha (ed.) Online Encyclopedia of Peace Education. New York: Columbia University, Teachers College.

Pratt, D. (1980). Curriculum: Design and development. New York: Harcourt, Brace, Jovanovich.

Syed Arabi Idid. (1998). Kaedah penyelidikan komunikasi dan sains sosial. Kuala Lumpur: Dewan Bahasa dan Pustaka.

Toh, S. H. (1997, September). Education for peace: Towards a millennium of well-being. In Paper for the Working Document of the International Conference on Culture of Peace and Governance (Maputo, Mozambique, 1-4 September, 1997).

UNICEF (1999a). The Future Global Agenda for Children: Imperatives for Twenty-First Century. E/ICEF/1999/10 (Executive Board Document).

UNICEF (1999b). Progress, Challenges and Future Strategies in Basic Education. E/ICEF/1999/14 (Paper tabled at June 1999 Executive Board Session).

Wei, C.Y. (2009). Relationship between learning styles and achievement of form four students in the subject of basic economics at a school in Kajang. Master's project, Bangi: The National University of Malaysia.

Wikipedia (2015). Peace Education. Retrieved at https://en.wikipedia.org/wiki/Peace_education. 